\title{
COMO ALUNOS DE CONTABILIDADE PERCEBEM A CONTRIBUIÇÃO DE CONTADORES PARA A ADOÇÃO DE PRÁTICAS DE SUSTENTABILIDADE E DE GREEN IT NAS ORGANIZAÇÕES
}

\author{
HOW ACCOUNTING STUDENTS PERCEIVE THE \\ CONTRIBUTION OF ACCOUNTANTS FOR THE ADOPTION OF \\ SUSTAINABILITY AND GREEN IT PRACTICES IN \\ ORGANIZATIONS
}

\section{CÓMO ALUMNOS DE CONTABILIDAD PERCIBEN LA CONTRIBUCIÓN DE CONTADORES PARA LA ADOPCIÓN DE PRÁCTICAS DE SOSTENIBILIDAD Y DE GREEN IT EN LAS ORGANIZACIONES}

Raphael Junger da Silva

Mestre em Ciências Contábeis - UFRJ, Rio de Janeiro, Brasil

Assessor de Conformidade do Tribunal Regional Federal da $2^{\text {a }}$. Região, Rio de Janeiro, Brasil. rjs.audit@gmail.com

\section{Monica Zaidan Gomes}

Doutora em Administração de Empresas - PUCRio, Rio de Janeiro, Brasil

Professora do Departamento de Contabilidade e do Programa de Pós-Graduação em Ciências

Contábeis da Faculdade de Administração e

Ciências Contábeis - Universidade Federal do Rio de Janeiro, Rio de Janeiro, Brasil

mrossi@facc.ufrj.br

\author{
Moacir Sancovschi \\ Doutor em Ciências em Administração - Instituto \\ Coppead de Administração, Rio de Janeiro, Brasil \\ Professor do Departamento de Contabilidade e do \\ Programa de Pós-Graduação em Ciências \\ Contábeis da Faculdade de Administração e \\ Ciências Contábeis - Universidade Federal do Rio \\ de Janeiro, Rio de Janeiro, Brasil \\ msancov@facc.ufrj.br
}

Contextus

ISSNe 2178-9258

Organização: Comitê Científico Interinstitucional Editor-Chefe: Diego de Queiroz Machado Avaliação: double blind review pelo SEER/OJS Recebido em 26/09/2018 Aceito em 12/11/2018 $2^{a}$ versão aceita em 28/01/2019 http://dx.doi.org/10.19094/contextus.v17i1.33815

\section{RESUMO}

Este estudo avaliou a importância de disciplinas sobre sustentabilidade e Tecnologia da Informação/Sistema de Informação (TI/SI) para formar a percepção de estudantes de graduação e pós-graduação stricto sensu em contabilidade, da Região Metropolitana do Rio de Janeiro, no tema sustentabilidade em TI/SI. Os resultados confirmam os achados da literatura de que muitos alunos de contabilidade chegam ao final do curso sem ter nenhum contato com essas disciplinas e que, na percepção dos respondentes, a contribuição mais importante dos contadores para a sustentabilidade em TI/SI é controlar e avaliar o desempenho de indicadores físicos e financeiros de TI. Por outro lado, uma das contribuições menos importantes foi reportar desempenho ambiental 
de TI para usuários externos. Ainda, a quantidade de disciplinas cursadas sobre TI/SI e sustentabilidade tem a capacidade de influenciar a percepção dos respondentes sobre a importância por eles atribuída aos temas.

Palavras-chave: sustentabilidade; TI/SI; disciplinas curriculares; percepção de estudantes; Contabilidade.

\begin{abstract}
This study evaluated the importance of sustainability and Information Technology/Information System (IT/IS) disciplines in building up perceptions of undergraduate and graduate accounting students' in the Metropolitan Region of Rio de Janeiro with respect to sustainability in IT/IS. The results confirm the findings of the literature that many accounting students reach the end of the course without any contact with theses disciplines and that, in the respondents' perception, the most important contribution of accountants to sustainability in IT/IS is controlling and evaluating the performance of physical and financial IT indicators. On the other hand, one of the least important contributions was reporting IT environmental performance to external users. Also, the number of subjects covered in IT/IS and sustainability throughout academic life of the students has the power to influence the respondents' perception of the importance they attribute to the subjects.
\end{abstract}

Keywords: sustainability; IT/SI; academic disciplines; student's perceptions; Accounting.

\title{
RESUMEN
}

Este estudio evaluó la importancia de las disciplinas de sostenibilidad y Tecnología de Información/Sistemas de Información (TI/SI) para la formación de la percepción de estudiantes de graduación y postgrado en contabilidad, de la Región Metropolitana de Río de Janeiro, en el tema sostenibilidad en TI/SI. Los resultados confirman los hallazgos de la literatura de que muchos alumnos de contabilidad llegan al final del curso sin tener ningún contacto con esas disciplinas y que, en la percepción de los encuestados, la contribución más importante de los contadores a la sostenibilidad en TI/SI es controlar y evaluar el desempeño de indicadores físicos y financieros de TI. Por otro lado, una de las contribuciones menos importantes fue reportar desempeño ambiental de TI para usuarios externos. Además, la cantidad de disciplinas cursadas de TI/SI y sostenibilidad tiene la capacidad de influir en la percepción de los respondedores sobre la importancia que ellos atribuyen al tema. Palabras clave: sostenibilidad; TI/SI; disciplinas curriculares; percepción de estudiantes; Contabilidad.

\section{INTRODUÇÃO}

O presente trabalho tem por objetivo avaliar a importância de cursar disciplinas sobre sustentabilidade e Tecnologia da Informação/Sistema de Informação (TI/SI) para a formação da percepção de estudantes de graduação e pós-graduação stricto sensu em contabilidade, da Região Metropolitana do Rio de Janeiro, com relação à contribuição dos contadores para a adoção de práticas de sustentabilidade em TI/SI nas organizações.

O papel dos contadores não é mais o de simples registradores de informações financeiras, preparadores de balanços ou mesmo auditores. Espera-se que os contadores também atuem como facilitadores ou apoiadores dos processos de tomada de decisão, envolvendo-se em temas relacionados a TI/SI e sustentabilidade. Isso exige habilidades gerenciais, mas também competências em tecnologia e em sistemas de informação, além de um olhar transversal e integrativo sobre sustentabilidade (EL-DALAHMEH, 2017; COYNE; COYNE; WALTER, 2017; SILVA; RODRIGUES, 2016; BRANDALISE et al., 2014).

Em geral, as instituições de ensino superior (IES) se esforçam para preparar os estudantes para os desafios da contemporaneidade, uma vez que possuir tais competências tornou-se fundamental para sua colocação no mercado de trabalho, mas - apesar desses 
esforços - os egressos ainda saem das universidades com deficiências de formação nos âmbitos mencionados, o que aumenta o risco de sua substituição por profissionais de outras áreas, em especial, de TI/SI (EL-DALAHMEH, 2017; COYNE; COYNE; WALTER, 2017).

No que tange à questão da sustentabilidade, pode-se dizer que os contadores são afetados, principalmente, porque "as preocupações provenientes das questões ambientais, em nível global, exercem pressão sobre a contabilidade tradicional para incorporar nesta a responsabilidade ambiental" (FEIL et al., 2017, p. 224). "Sustentabilidade empresarial não é mais uma reflexão filantrópica [...], mas sim uma nova abordagem que deve ser incorporada ao planejamento estratégico da empresa" (SILVA; RODRIGUES, 2016, p. 3), de forma a mitigar os riscos ambientais inerentes ao negócio.

Essas questões têm desempenhado uma crescente influência nas tomadas de decisões organizacionais (FEIL et al., 2017), e o aprimoramento do conhecimento do profissional contábil a seu respeito é necessário "para auxiliar no direcionamento das organizações com vistas a produção mais limpa e da incorporação dos registros dos impactos ambientais nas demonstrações financeiras" (FEIL et al., 2017, p. 239).

Existe a expectativa de que os contadores contribuam, por meio do aprimoramento da Contabilidade Gerencial Ambiental - CGA, para a evolução da performance das empresas, pois aquela disciplina "oferece uma oportunidade para uma integração holística das questões ambientais nas estratégias e práticas das empresas e para alinhar os processos e atividades corporativos com a estratégia ambiental" (GUENTHER; ENDRIKAT; GUENTHER, 2016, p. 148 , tradução dos autores).

No tocante à TI/SI, as demandas impostas aos profissionais da contabilidade cresceram muito nas últimas 2 (duas) décadas, solicitando que os contadores participassem de projetos de planejamento e implantação de sistemas de informações contábeis, gerenciais, tributários e ambientais com capacidade de integrar, acompanhar, coletar, processar e produzir informações financeiras e não financeiras para toda a sorte de processos de tomada de decisão da média e alta administração nas organizações.

Hoje, Enterprise Resource Planning - ERP, Extensible Business Resource Language - XBRL e Business Inteligence - BI, por exemplo, são temas de trabalho e estudo (RICCIO, 2001; REGINATO; NASCIMENTO, 2007; PETRINI; POZZEBON, 2009; LIU; O’FARRELL, 2013; KANELLOU; SPATHIS, 2013; FARIAS, 2014; SILVA, 2016; 
FERREIRA et al., 2018) dos profissionais e acadêmicos da contabilidade, em especial na disciplina de Sistemas de Informações Contábeis.

Apesar da importância do desenvolvimento de competências e da compreensão das novas funções do contador nas organizações com relação a TI/SI e sustentabilidade e suas funções gerenciais associadas, as disciplinas que tratam desses temas ainda não tiveram o devido destaque no currículo das universidades e, não raras vezes, são as menos contempladas pelos currículos das IES. Portanto, percebe-se um verdadeiro desequilíbrio na formação dos egressos em comparação com as demais áreas curriculares, em que pese haja grande interesse dos alunos por essas disciplinas em virtude do reconhecimento da demanda do mercado de trabalho e da sociedade (CALIXTO, 2006; CZESNAT; CUNHA; DOMINGUES, 2009; ERFURTH et al., 2009; CAVALCANTE et al., 2011; SANTOS; DOMINGUES; RIBEIRO, 2011; VARELO et al., 2011; WEIZENMANN, 2011; DALLABONA; CUNHA; RAUSCH, 2012; DREHER; SEVEGNANI, 2012; CAMPOS; LEMES, 2014; CONCEIÇÃO et al., 2014; ALMEIDA et al., 2015).

Não são raros os estudos na área de educação contábil que analisam o perfil e as competências esperadas dos contadores diante dos novos desafios da profissão, bem como a adequação das grades curriculares dos cursos de graduação em contabilidade às novas exigências da sociedade (OWEN, 2013; YU; CHURYK; CHANG, 2013; SILVA, 2014; LOW et al., 2016; PINCUS et al., 2017) pois, uma vez que "o perfil do graduado em contabilidade é resultado de como o currículo foi projetado e implementado" (PARAWIYATI et al., 2014, p. 129, tradução dos autores), "a atualização das grades curriculares é relevante para o desenvolvimento dos cursos" (PARAWIYATI et al., 2014, p. 128, tradução dos autores), o que traz bastante relevância aos resultados apresentados por esses trabalhos.

Nesses estudos, diversos parâmetros são utilizados para avaliar a necessidade de atualização ou melhorias nos currículos, neles incluem-se as expectativas do mercado (empregadores) e os modelos prescritos por órgãos colegiados ligados à profissão (UNCTAD, 2011; MINISTÉRIO DA EDUCAÇÃO, 2004; CONSELHO FEDERAL DE CONTABILIDADE, 2009; IFAC, 2017). Entre os modelos mais estudados está o Currículo Mundial Revisado - CMR (UNCTAD, 2011), que será utilizado na construção do quadro teórico desta pesquisa, em especial no tocante às funções e competências esperadas dos contadores em TI/SI e sustentabilidade. 
Outra parte do referido quadro teórico será complementada com base na literatura sobre Green IT (TI Verde), tendo em vista tratar-se de um tema contemporâneo e que integra, simultaneamente, conceitos de TI/SI e sustentabilidade. Essa característica da Green IT permite a análise do entendimento sobre a articulação entre as funções e competências esperadas dos egressos de ciências contábeis com as estratégias e práticas de um tema contemporâneo de TI/SI. Ademais, possibilita examinar a influência do histórico de disciplinas cursadas de TI/SI e Sustentabilidade, ao longo da vida acadêmica dos respondentes, nas suas percepções acerca do tema.

Desse modo, propõe-se a seguinte questão de pesquisa: Qual a importância de cursar disciplinas sobre sustentabilidade e Tecnologia da Informação/Sistema de Informação (TI/SI), na opinião de alunos de contabilidade, a respeito da contribuição dos contadores para a adoção de práticas de sustentabilidade em TI/SI nas organizações?

Esse estudo contribui para a literatura ao examinar como a ausência ou baixa incidência de disciplinas cursadas sobre sustentabilidade e TI/SI influencia a percepção de importância atribuída pelos discentes de contabilidade às práticas de sustentabilidade em TI/SI nas organizações. Desse modo, essa pesquisa contribui para a discussão acerca da lacuna de competências nas grades curriculares de cursos de graduação e pós-graduação stricto sensu de Contabilidade, especificamente sobre sustentabilidade e SI/TI e acerca do futuro da profissão contábil com relação ao tema da sustentabilidade.

\section{REFERENCIAL TEÓRICO}

\subsection{A Importância de Disciplinas sobre TI/SI e Sustentabilidade e sua Deficiência nas Grades Curriculares de Ciências Contábeis no Brasil}

A demanda por contadores com conhecimentos de TI/SI é cada vez maior, no Brasil e no mundo. O que se espera dos egressos de contabilidade não é mais a mera operação de planilhas eletrônicas para a construção de gráficos e tabelas (COYNE; COYNE; WALTER, 2017; KRAHEL; VASARHELYI, 2014). A disseminação dos ERPs permitiu aos colaboradores da organização, mesmo aqueles não graduados em Ciências Contábeis, que extraíssem relatórios para o seu uso cotidiano de forma fácil e eficaz, assim atendendo as suas demandas primárias sem a necessidade de solicitar o auxílio de um profissional de contabilidade para acessar e interpretar informações financeiras já parametrizadas internamente nos ERPs, ou padronizadas pelas normas contábeis internacionais. 
Desta forma, a satisfação das necessidades primárias dos usuários por aplicativos de planilhas eletrônicas ou ERPs amigáveis gera, no presente, a tendência de redução da demanda por contadores no suporte a decisões gerenciais mais triviais. Por outro lado, as demandas mais complexas relacionadas ao uso de ferramentas de Mineração de Dados (Data Mining), o entendimento das grandes massas de dados (Big Data), conhecimento de XBRL, arquitetura da informação, avaliação de investimentos em TI, mapeamento de fluxo de dados, segurança da informação, e BI (Business Intelligence), são "expertises" consideradas vitais para o sucesso profissional dos egressos de ciências contábeis no longo prazo (KRAHEL; VASARHELYI, 2014; BOULIANNE, 2016; SLEDGIANOWSKI; GOMAA; TAN, 2017; MCKINNEY JR; YOOS II; SNEAD, 2017; PINCUS et al., 2017).

As IES brasileiras não têm conseguido acompanhar as mudanças no cenário tecnológico e os cursos de ciências contábeis no Brasil nem sempre oferecem disciplinas ligadas a TI/SI e, quando as oferecem, muitas vezes o fazem na forma de eletivas/optativas, em pouca quantidade, ou por meio de currículos incipientes, que geralmente não incluem tópicos mais avançados como os anteriormente citados (CZESNAT; CUNHA; DOMINGUES, 2009; ERFURTH et al., 2009; CAVALCANTE et al., 2011; SANTOS; DOMINGUES; RIBEIRO, 2011).

Tal situação coloca em risco o futuro profissional dos egressos de ciências contábeis no Brasil, porque sem conhecimentos, teóricos e técnico-instrumentais, acabam sendo profissionais facilmente "substituíveis" no mercado de trabalho, na medida em que muitas organizações já preferem contratar profissionais na área de TI/SI e treiná-los em negócios e finanças, em vez de contratar contadores e treiná-los em TI/SI, tendo em vista o maior "gap" de formação a ser preenchido pelos últimos (COYNE; COYNE; WALTER, 2017).

Simultaneamente ao incremento das novas exigências de perfil profissional relacionadas a TI/SI, também aumentou a procura por profissionais contábeis capazes de lidar com temas relacionados ao meio ambiente e à sustentabilidade, em virtude do aumento da demanda por parte da sociedade e dos órgãos reguladores por mais responsabilidade ambiental nos negócios, o que tem afetado diretamente a profissão e exigido o desenvolvimento, por parte dos contadores, de competências que possibilitem lidar com o novo contexto social de forma integrativa (FRIEDMAN, 2007; PARAWIYATI et al., 2014; ALMEIDA et al., 2015; CARMO; GOMES; MACEDO, 2015; FEIL et al., 2017, p. 224). 
As organizações esperam dos profissionais da contabilidade a capacidade de auxiliar na interação da organização perante os acontecimentos internos e externos relativos à responsabilidade social, seja auxiliando no planejamento e direcionamento de seus objetivos e estratégias de investimento, na comunicação da sua imagem, no monitoramento de suas estratégias, e, principalmente, na conformidade dos relatórios ambientais e sociais que são instrumentos de prestação de contas e de comunicação das empresas perante a sociedade e dão transparência às atividades de impacto socioambiental das organizações, inclusive para os órgãos de fiscalização (DALLABONA; CUNHA; RAUSCH, 2012; CONCEIÇÃO et al., 2014).

Da mesma forma que ocorre com as disciplinas sobre TI/SI, a questão da sustentabilidade continua sendo tratada de forma periférica, visto que poucas IES oferecem disciplinas sobre sustentabilidade em suas grades curriculares. Dallabona, Cunha e Rausch (2012, p. 7) afirmam que "a inserção da contabilidade ambiental nas matrizes curriculares ainda é incipiente, visto que, das 31 universidades da região sul do Brasil com os melhores conceitos do ENADE/2006, somente nove têm alguma disciplina voltada à contabilidade ambiental". Do mesmo modo, Conceição et al. (2014, p. 4) verificaram que "há carência de discussão do tema de Contabilidade Social e Ambiental nos componentes obrigatórios da matriz curricular”. Ressalte-se que há estados no Brasil onde nenhuma universidade oferece essas disciplinas, apesar do interesse dos alunos nessas matérias (WEIZENMANN, 2011; VARELO et al., 2011; DALLABONA; CUNHA; RAUSCH, 2012; CONCEIÇÃO et al., 2014).

Os reflexos dessas deficiências curriculares não colocam em risco apenas a carreira dos egressos dos cursos de contabilidade e as empresas que ficam carentes de mão de obra qualificada. Há reflexos também na academia, onde a produção cientifica é diretamente afetada, especialmente em temas contemporâneos e interdisciplinares como TI Verde.

A exemplo, pode-se citar as constatações do estudo bibliométrico realizado por Silva, Soares e Gomes (2017) com o objetivo de traçar um panorama das contribuições nacionais em periódicos, dissertações, teses e anais de congressos vinculadas à TI Verde, no período de 2007 a 2016, que verificou:

[...] na contramão do que se pressupôs ao início dessa pesquisa, em que pese a área de Administração e Ciências Contábeis esteja representada nas estatísticas, cumpre ressaltar que não identificamos entre os trabalhos levantados qualquer referência específica ao arcabouço teórico das Ciências Contábeis, em 
especial, aquele apresentado pela Contabilidade Gerencial Ambiental (item 2.4) como sistema de apoio à decisão ambiental para a TI verde.

[...] no que tange à relação da TI verde com as Ciências Contábeis, verificou-se que, embora a contabilidade possua um arcabouço teórico capaz de oferecer suporte às três áreas de pesquisa da TI verde, não há evidências de que pesquisadores brasileiros estejam engajados em pesquisas nessa vertente, o que representa uma janela de oportunidades de pesquisa a ser explorada. (SILVA; SOARES; GOMES, 2017, p. 13-15)

Dessa forma, fica evidenciado que a área de contabilidade tem se envolvido muito pouco em pesquisas sobre questões envolvendo sustentabilidade em TI, deixando de lado um campo profícuo de estudo e trabalho acadêmicos.

Espera-se dos gestores que demandem dos profissionais das ciências contábeis auxílio no processo de tomada de decisão em questões que exigem a articulação de conhecimentos de diversas áreas num esforço interdisciplinar, nesse caso, entre contabilidade, TI e Sustentabilidade, porém, considerando a baixa produção acadêmica da contabilidade nacional em Green IT, não há evidências, no momento, de que os egressos de ciências contábeis no Brasil estejam preparados para essas demandas.

\subsection{TI Verde (Green IT)}

A questão da sustentabilidade em TI/SI surgiu nos anos 2000 devido à necessidade de compatibilizar os crescentes investimentos em TI/SI nas organizações com as demandas sociais de sustentabilidade nos negócios. Baseia-se numa abordagem ampla das atividades organizacionais com foco em resultados sustentáveis, por meio de práticas de arquitetura, construção, manutenção e descarte de computadores, servidores e subsistemas associados de forma eficiente e eficaz, com o mínimo ou nenhum impacto sobre o meio ambiente (MURUGESAN, 2008; SAYEED; GILL, 2008; MOLLA et al., 2008; MATTOS; LAURINDO, 2015; WALTERBUSCH; MARTENS; TEUTEBERG, 2015; DALVIESFAHANI; RAMAYAH; NILASHI, 2017). Tal abordagem foi conceitualmente chamada de Green IT e consiste no estudo e desenvolvimento de tecnologias para reduzir o impacto das atividades da área de TI no meio ambiente.

Dentre as estratégias estudadas pelas organizações envolvidas em práticas de Green IT, a literatura destaca 3 (três) áreas principais, são elas: (1) gestão de ativos de TI, (2) 
eficiência no consumo de energia, e (3) permitir "práticas verdes" através da utilização da TI (BOSE; LUO, 2011).

A estratégia de gestão de ativos de TI tem como principal abordagem a concepção de Green Data Centers, nos quais se adotam práticas sustentáveis que passam pelo projeto de refrigeração otimizado para o Data Center - DC, pela adequada arquitetura de hardware e software com uso da computação paralela, pela adequada gestão do ciclo de vida dos ativos de TI, inclusive gestão do $e$-waste, pela consolidação e virtualização de servidores e storages, pela escolha do local de instalação do DC com vistas à otimização da refrigeração, e pela seleção de fontes de energia limpa/renovável (REIS, 2009; MÓR et al., 2010; BOSE; LUO, 2012; MAITINO NETO; FAXINA, 2014; JIN et al., 2016; COOK et al., 2017; DI SALVO et al., 2017; SILVA; SOARES; GOMES, 2017).

A eficiência no consumo energético é considerada uma estratégia central em Green IT, em que as organizações adotam práticas de terceirização total ou parcial da infraestrutura e/ou serviços de TI, por meio da contratação de provedores de serviços de nuvem alocados em Data Centers que atendam às melhores práticas de sustentabilidade em TI, de forma a reduzir ao máximo o nível de emissões de carbono e os custos de manutenção da TI.

Através das práticas de terceirização total ou parcial da infraestrutura e/ou serviços de TI, as organizações podem dedicar mais tempo às suas estratégias organizacionais e atividades fim, além de reduzir ou até mesmo eliminar os custos com aquisição, manutenção e descarte de equipamentos, aluguel de espaço para instalação de DC, manutenção de equipes técnicas de suporte e atendimento de TI, e energia elétrica do DC (PAWLISH; VARDE, 2010; BOSE; LUO, 2011; CHAVES, 2011; MARTINS, 2012; RICHTER, 2012; WESTPHALL; VILLARREAL, 2013; WILLIAMS; THOMOND; MACKENZIE，2013; VIEIRA; MEIRELES; CUNHA, 2015; JIN et al., 2016; DI SALVO et al., 2017; SILVA; SOARES; GOMES, 2017).

"Práticas verdes" em TI referem-se à adoção de estratégias gerenciais de incentivo às mudanças comportamentais e tecnológicas por parte dos colaboradores de forma a tornar as atividades e operações da organização mais amigáveis ao meio ambiente (BOSE; LUO, 2011). Para tanto, as organizações investem, principalmente, em sistemas habilitados a coletar e processar dados de natureza monetária e não monetária relativos a indicadores ambientais, estabelecidos por meio de parâmetros internos (gerenciais) ou externos (leis e regulamentos). 
Esses sistemas destinam-se a gerar relatórios para fins de acompanhamento de performance da estratégia ambiental por parte de gestores e funcionam como ferramenta de apoio à tomada de decisão gerencial ambiental. Ademais, operam reportes padronizados para usuários externos, que satisfazem as necessidades dos órgãos reguladores e podem ser utilizados, também, como diferencial competitivo e por meio da promoção do marketing verde junto aos consumidores (RODRIGUES, 2010; OLIVEIRA; PINHEIRO, 2010; CHANG et al., 2011; PARAWIYATI et al., 2014; STINDT et al., 2014; WALTERBUSCH; MARTENS; TEUTEBERG, 2015; CASTRO et al., 2016; GUENTHER; ENDRIKAT; GUENTHER, 2016; JNR; MAJID, 2016; MERHOUT; CALLISON; SCHILLER, 2016; SILVA; SOARES; GOMES, 2017).

\subsection{Diretrizes para Formação de Contadores em TI/SI e Sustentabilidade no Currículo Mundial (UNCTAD, 2011)}

O Currículo Mundial Revisado (UNCTAD, 2011, p. 40-41, tradução dos autores) destaca, no seu item 2.1.1., subitem (d), as funções dos contadores em TI/SI, tanto como usuários/clientes de TI/SI, quanto como prestadores de serviço/fornecedores à área de TI/SI. Assim, podem ser consideradas funções dos contadores no que diz respeito à TI/SI: (i) Especificar tipos e características de Hardware de usuário final; (ii) Atuar nos Comitês de TI/SI; (iii) Participar de Decisões estratégicas de TI, tais como: Alocação de Recursos; Aquisição de hardware; Disponibilidade de aplicações; Instalação de infraestrutura; Decisões entre desenvolver X comprar; Decisões entre terceirizar X internalizar; Automatização dos processos de trabalho; Reengenharia dos processos de trabalho; Adoção de novas tecnologias; Uso estratégico da TI; Terceirização.

Com relação às competências a serem adquiridas pelos estudantes de contabilidade durante o curso para que atuem de forma sustentável em TI/SI e agreguem valor às suas atividades, segundo a UNCTAD (2011, p. 37-38, tradução dos autores), ao final do módulo de “Tecnologia da Informação" o estudante deve: (i) entender o que é TI, e o que os profissionais de TI fazem; (ii) entender quais são os pontos de interação entre a contabilidade e as áreas funcionais de TI, por exemplo, onde a contabilidade pode auxiliar a TI; (iii) entender o funcionamento de sistemas de grande porte; (iv) entender seu papel no processo de tomada de decisão e sua relação com a organização; (v) descrever as ferramentas de auxílio a gerenciamento de projetos eficientes; (vi) discutir procedimentos que permitam a manutenção 
correta e tempestiva dos sistemas; (vii) compreender os ciclos de upgrade e substituição de equipamentos; (viii) compreender os problemas do gerenciamento dos recursos existentes (inventário e gestão da manutenção dos microcomputadores); (ix) compreender a importância do comércio eletrônico no ambiente de negócios atual, como funciona, quanto custa, e seus impactos na organização; $(\mathrm{x})$ compreender as implicações relacionadas às mudanças de configuração de equipamentos, software etc.

Por fim, o modelo curricular da UNCTAD (2011) não trata as questões de sustentabilidade na forma de capítulo (bloco), nos moldes dos tópicos de TI, mas sim como questões a serem consideradas nos quatro blocos curriculares propostos: (1) conhecimentos organizacionais e de negócios; (2) tecnologia da informação; (3) contabilidade financeira básica e tópicos relacionados; e (4) contabilidade financeira avançada e tópicos relacionados. Neste sentido, identificam-se referências às questões de sustentabilidade nos módulos (blocos) de organizações e seu ambiente estrutural e político (1.3.4.), preparação dos diferentes tipos de demonstrações financeiras e outras questões contábeis especiais aplicação de IAS e IFRS (3.2.2.), normativos empresariais (3.7), preocupações contabilísticas emergentes (3.10.1), relatórios financeiros para tópicos especializados (4.1.1.), objetivos não financeiros das empresas, como objetivos ambientais e sociais (4.2.7.), auditoria ambiental (4.5.6.), e quadro da gestão financeira (4.6.2.).

No Quadro 1, relacionam-se as funções esperadas dos profissionais da contabilidade, indicadas pelo CMR (UNCTAD, 2011), para auxílio às estratégias e às práticas sustentáveis de TI/SI nas organizações. As estratégias de TI verde vistas no item 2.2 são descritas no trabalho de Bose e Luo (2011). No que diz respeito às práticas de TI verde, o quadro 1 aponta a respectiva fonte bibliográfica de cada prática. A aquisição das competências elencadas no CMR (UNCTAD, 2011) permite aos contadores o desempenho eficaz de suas funções com relação a TI/SI, isto é, o domínio do conjunto completo de competências é a base para a atuação profissional dos contadores, apoiando cada uma das estratégias de TI Verde e suas respectivas práticas. 
Quadro 1 - Resumo das Funções dos Contadores no Auxílio às Estratégias e Práticas de Sustentabilidade em TI/SI

\begin{tabular}{|c|c|c|}
\hline Funções dos Contadores & $\begin{array}{l}\text { Estratégias de TI } \\
\text { Verde }\end{array}$ & Práticas de TI Verde \\
\hline $\begin{array}{l}\text { - Especificar tipos } \\
\text { características de hardware de } \\
\text { usuário final } \\
\text { - Participar de decisões } \\
\text { estratégicas quanto à alocação de } \\
\text { recursos de TI/SI (UNCTAD, } \\
\text { 2011): } \\
\text { - Aquisição de hardware } \\
\text { - Disponibilidade } \\
\text { aplicações de } \\
\text { - Instalação } \\
\text { infraestrutura } \\
\text { - Decisões } \\
\text { desenvolver X comprar } \\
\text { - Decisões entre terceirizar } \\
\text { X internalizar } \\
\text { - Automatização } \\
\text { processos de trabalho } \\
\text { - Reengenharia } \\
\text { processos de trabalho } \\
\text { - Adoção do de novas } \\
\text { tecnologias }\end{array}$ & $\begin{array}{lrr}\text { GESTÃO } & \text { DE } \\
\text { ATIVOS } & \text { DE } & \text { TI } \\
\text { (BOSE e } & \text { LUO, } \\
2011) & & \end{array}$ & $\begin{array}{l}\text { - Contratar energia } \\
\text { limpa/renovável (COOK et al., } \\
\text { 2017); } \\
\text { - Otimizar a refrigeração (DI } \\
\text { SALVO et al., 2017); } \\
\text { - Adotar computação paralela } \\
\text { (MÓR et al., 2010); } \\
\text { - Gerir o ciclo de vida dos } \\
\text { equipamentos de TI: } \\
\text { a) especificar compras } \\
\text { sustentáveis de TI (SILVA; } \\
\text { SOARES; GOMES, 2017) } \\
\text { b) gerir o e-waste (MAITINO } \\
\text { NETO; FAXINA, 2014); } \\
\text { - Virtualizar/ Consolidar } \\
\text { servidores e storages (BOSE e } \\
\text { LUO, 2012). }\end{array}$ \\
\hline $\begin{array}{l}\text { - Participar } \text { de } \\
\text { estratégicas de decisões } \\
\text { terceirização (UNCTAD, 2011) }\end{array}$ & $\begin{array}{lr}\text { EFICIENCIA } & \text { NO } \\
\text { CONSUMO DE } & \text { DE } \\
\text { ENERGIA (BOSE e } \\
\text { LUO, 2011) }\end{array}$ & $\begin{array}{l}\text { - Migrar para Cloud Computing } \\
\text { (RICHTER, 2012). }\end{array}$ \\
\hline $\begin{array}{l}\text { - Atuar em Comitês de TI/SI } \\
\text { (UNCTAD, 2011) } \\
\text { - Participar de decisões quanto ao } \\
\text { uso estratégico da TI (UNCTAD, } \\
\text { 2011) }\end{array}$ & $\begin{array}{l}\text { "PRÁTICAS } \\
\text { VERDES" EM TI } \\
\text { (BOSE e } \text { LUO, } \\
2011)\end{array}$ & $\begin{array}{l}\text { - Monitorar o consumo de } \\
\text { energia e emissões de poluentes } \\
\text { (JNR e MAJID, 2016); } \\
\text { - Controlar e avaliar o } \\
\text { desempenho de indicadores } \\
\text { físicos e financeiros } \\
\text { (GUENTHER; ENDRIKAT; } \\
\text { GUENTHER, 2016) } \\
\text { - Reportar desempenho } \\
\text { ambiental para usuários } \\
\text { externos (PARAWIYATI et al., } \\
\text { 2014). }\end{array}$ \\
\hline
\end{tabular}

Fonte: elaboração própria.

A partir do Quadro 1 foi construído um questionário fechado baseado numa escala Likert de 5 pontos, destinado a avaliar a importância que os alunos de contabilidade atribuem à contribuição dos contadores para a adoção de práticas de sustentabilidade em TI/SI nas organizações. Ainda, foram incluídas questões para levantamento da quantidade de disciplinas 
cursadas de Sustentabilidade e TI/SI, além de dados sobre o curso atual dos respondentes (graduação, mestrado ou doutorado), que foram utilizadas para analisar a associação daquela avaliação com o número de disciplinas cursadas de sustentabilidade e TI/SI durante a vida acadêmica dos alunos.

\section{METODOLOGIA}

Tendo em vista tratar-se de pesquisa exploratória e descritiva (VERGARA, 2006), este trabalho investigou, diretamente no campo, as percepções de uma amostra não probabilística de 361 alunos do último ano de cursos de graduação e pós-graduação em ciências contábeis de 8 (oito) diferentes Instituições de Ensino Superior (IES), públicas e privadas, localizadas na Região Metropolitana do Rio de Janeiro, acerca da importância da "contribuição dos contadores para as práticas de sustentabilidade em tecnologia e sistemas de informação (TI/SI)", buscando analisar a influência da quantidade de disciplinas cursadas de TI e Sustentabilidade sobre a percepção dos respondentes acerca do tema. A coleta de dados ocorreu nos meses de outubro e novembro de 2017. As práticas pesquisadas estão relacionadas no Quadro 2.

Quadro 2 - Práticas de Sustentabilidade em Tecnologia e Sistemas de Informação (TI/SI)

P1 - Contratar energia limpa/renovável.

P2 - Otimizar a refrigeração dos Data Centers.

P3 - Adotar computação paralela.

P4 - Gerir o ciclo de vida dos equipamentos de TI.

P5 - Especificar compras sustentáveis de TI.

P6 - Gerir o lixo eletrônico.

P7 - Virtualizar/Consolidar servidores e dispositivos de armazenamento de dados.

P8 - Migrar para Computação em Nuvem.

P9 - Monitorar o consumo de energia e emissões de poluentes.

P10 - Controlar e avaliar o desempenho de indicadores físicos e financeiros de TI.

P11 - Reportar desempenho ambiental de TI para usuários externos.

Fonte: elaboração própria.

O questionário continha duas (2) seções. Na primeira, os respondentes indicam a importância atribuída à contribuição dos contadores para as práticas de sustentabilidade em TI/SI. Na segunda, há perguntas sobre o perfil do respondente, incluindo a quantidade de disciplinas cursadas sobre sustentabilidade (p. ex., Ética, Contabilidade Ambiental, Negócios Sociais etc.) e TI/SI (por ex. Informática Aplicada à Contabilidade, Sistemas de Informação Contábeis, Auditoria de Sistemas etc.). 
Os dados coletados foram analisados por meio de tabelas de distribuições de frequência, e testes não paramétricos U de Mann Whitney, destinados a identificar diferenças significativas entre as respostas de grupos de respondentes separados por quantidade de disciplinas sobre TI/SI e sustentabilidade. Utilizou-se o teste Alfa de Cronbach para avaliar se o instrumento de medição era confiável.

\section{ANÁLISE E DISCUSSÃO DOS RESULTADOS}

Iniciando pela análise descritiva da amostra, no que tange ao número de disciplinas de TI (GRÁFICO 1) cursadas pelos estudantes da amostra, observa-se que 64,3\% (31,9\% + $32,4 \%$ ) dos alunos cursou no máximo 1 (uma) disciplina de TI durante a graduação ou pósgraduação. Por outro lado, 35,7\% (27,4\% + 8,3\%) cursaram 2 (duas) ou mais disciplinas. Ressalta-se que 31,9\% (115/361) dos respondentes declararam ter chegado a uma fase avançada (último ano de graduação ou pós-graduação) de sua vida acadêmica sem ter tido nenhum contato com disciplinas de TI. O percentual elevado indica que a disciplina pode não ter sido oferecida ou se foi oferecida, os alunos não se sentiram motivados a cursá-la.

Gráfico 1 - Qtd. Disciplinas de TI

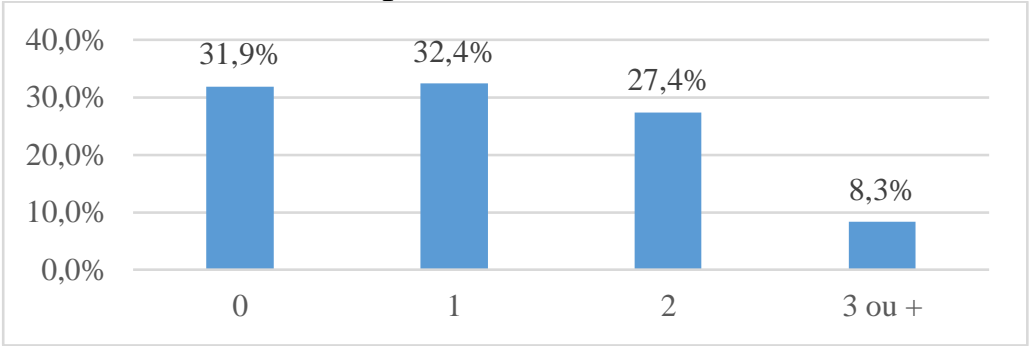

Fonte: elaboração própria.

Quanto ao número de disciplinas sobre Sustentabilidade (GRÁFICO 2) cursadas pelos estudantes da amostra, observa-se que 72,6\% (27,4\% + 45,2\%) dos alunos cursou no máximo 1 (uma) disciplina sobre Sustentabilidade durante a graduação ou pós-graduação. De outra parte, $27,4 \%(21,0 \%+6,4 \%)$ cursaram 2 (duas) ou mais disciplinas. Mais uma vez, ressaltase que 27,4\% (99/361) dos respondentes declararam ter chegado a uma fase avançada (último ano de graduação ou pós-graduação) de sua vida acadêmica sem ter tido contato com nenhuma disciplina sobre Sustentabilidade. 
Gráfico 2 - Quantidade de disciplinas sobre sustentabilidade

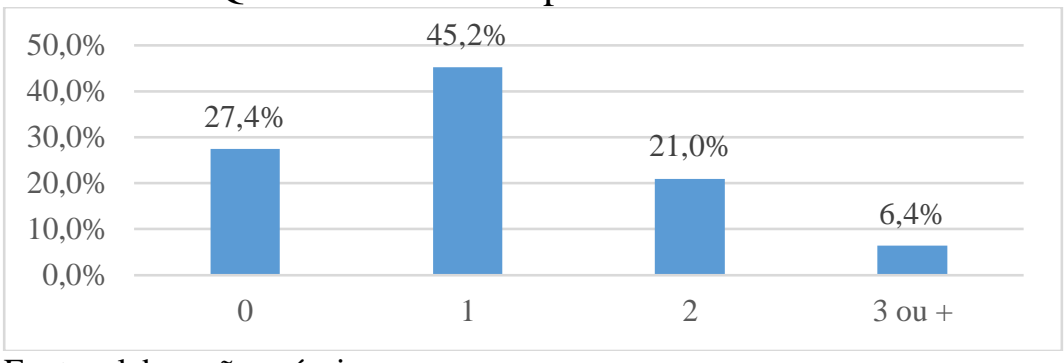

Fonte: elaboração própria.

Quanto ao tipo de IES, a maior parte dos respondentes, 55,7\% (201/361), é de estudantes de IES privadas, enquanto uma parcela um pouco menor, 44,3\% (160/361), é de estudantes de IES públicas.

Quando se analisa o curso atual dos respondentes, verifica-se que 93,1\% (336/361) são graduandos e apenas 6,9\% (25/361) são pós-graduandos, incluindo alunos de mestrado (21) e doutorado (4). Cite-se o fato de que existem na Região Metropolitana do Rio de Janeiro apenas 2 (duas) IES que oferecem cursos de pós-graduação stricto sensu em Ciências Contábeis, e uma delas, a UERJ, esteve em greve durante todo o período em que foi realizada a coleta de dados, o que acentuou o desequilíbrio da amostra neste ponto.

As Tabelas 1 e 2 apresentam as distribuições de frequências das respostas da seção do questionário acerca da "Percepção sobre a contribuição dos contadores para as práticas de sustentabilidade em tecnologia e sistemas de informação (TI/SI)". A Tabela 1 refere-se às duas amostras independentes ATE1_TI (Cursou até 1 disciplina de TI) e MAIS_TI (Cursou 2 ou mais disciplinas de TI). Já a Tabela 2 fornece as frequências das amostras independentes ATE1_SUST (Cursou até 1 disciplina sobre sustentabilidade) e MAIS_SUST (Cursou 2 ou mais disciplinas sobre sustentabilidade). Além das categorias de respostas 1 a 5 , onde " $1=$ nenhuma importância" e " 5 = extrema importância", também foi possível assinalar a categoria “Não sei responder”. Nas duas Tabelas, as modas das respostas estão sombreadas.

Na Tabela 1, de forma geral, a maioria dos respondentes percebe a importância da contribuição dos contadores para as práticas de sustentabilidade em TI/SI, pois, em ambas as amostras, todas as práticas obtiveram mais de $50 \%$ de respostas nas categorias 2 a 5 , demonstrando algum grau de importância percebida.

Sobressai que, independentemente da quantidade de disciplinas cursadas de TI/SI, mais de $20 \%$ dos respondentes não sabem avaliar a importância da contribuição dos contadores para a adoção da computação paralela (P3), revelando uma boa oportunidade de aprimoramento das disciplinas de TI/SI dos cursos de Contabilidade. Outro ponto, que 
também pode ser revisto nos currículos de Contabilidade, trata da refrigeração de Data Centers (P2) para assegurar o bom funcionamento dos equipamentos. A introdução da computação paralela na concepção da arquitetura de hardware e software "é o fator crítico na obtenção de processamento altamente eficiente e escalável” (MÓR et al., 2010, p. 348). Além disso, a energia elétrica requerida para resfriar os equipamentos de TI é um item com grande potencial de influenciar no consumo de energia total de um DC, representando entre $33 \%$ e $50 \%$ dos custos totais de manutenção dos DC (JIN et al., 2016).

Em ambas as amostras, destacam-se os percentuais superiores a $20 \%$ de "nenhuma importância" da contribuição dos contadores para a gestão do lixo eletrônico (P6), sendo a única prática que possui a moda das respostas na categoria sem importância. Isso suscita preocupação com o possível desconhecimento dos respondentes sobre os elementos presentes na composição de diversos equipamentos eletroeletrônicos, que "na maioria das vezes acabam jogados em lixões pelo mundo" (MAITINO NETO; FAXINA, 2014), e reforça a necessidade de aprimorar o conteúdo das disciplinas de TI/SI dos cursos de Contabilidade. Ademais, em ambas as amostras, os menores percentuais de "nenhuma importância" são atribuídos à contribuição dos contadores para "Controlar e avaliar o desempenho de indicadores físicos e financeiros de TI" (P10), ficando esta assertiva em primeiro lugar quando somadas as frequências das categorias de respostas de elevada importância (4 e 5), tanto para ATE1_TI quanto para MAIS_TI, totalizando 55,6\% e 58,1\%, respectivamente.

Sublinhe-se que a porcentagem de respostas relativas à contribuição dos contadores no reporte do desempenho ambiental de TI para usuários externos (P11) ficou em sétimo lugar em ambas as amostras, com 72,4\% de respostas nas categorias de elevada importância (4 e 5) para ATE1_TI e 74,4\% para MAIS_TI. Destaca-se que os resultados das estratégias e práticas de Sustentabilidade em TI/SI são diretamente observados nos demonstrativos socioambientais das organizações, permitindo que acionistas, clientes, fornecedores e demais partes interessadas da sociedade os avaliem. (PARAWIYATI et al., 2014).

A comparação das duas amostras, também revela outras diferenças. Há aumento da incidência de respostas de média a elevada importância na amostra MAIS_TI (categorias 3 a 5). A Tabela 1 revela que em ATE1_TI há três (3) modas das respostas na categoria de média importância (P5, P7 e P8) e quatro (4) nas categorias de elevada importância (P1, P4, P10 e P11). Já em MAIS_TI observam-se uma (1) moda das respostas na categoria de média importância (P2) e nove (9) nas categorias de elevada importância (P4, P5, P6, P7, P8, P9, 
P10 e P11). Os respondentes não apresentaram clara definição quanto à importância atribuída às contribuições dos contadores para as práticas de sustentabilidade em TI/SI, ainda que muitas das modas estejam na categoria de respostas de extrema importância (5), sugerindo maior atribuição de importância para essas práticas de sustentabilidade, em detrimento das demais.

Tabela 1 - Importância da contribuição dos contadores para as práticas de TI/SI Verde com respondentes agrupados por número de disciplinas de TI/SI cursadas (Frequência de respostas em $\%$ )

\begin{tabular}{|c|c|c|c|c|c|c|c|c|c|c|c|c|}
\hline & \multicolumn{6}{|c|}{ ATE1_TI (até 1 disciplina) } & \multicolumn{6}{|c|}{ MAIS_TI ( 2 ou mais disciplinas) } \\
\hline & \multicolumn{6}{|c|}{ Respostas } & \multicolumn{6}{|c|}{ Respostas } \\
\hline & 1 & 2 & 3 & 4 & 5 & NSR & 1 & 2 & 3 & 4 & 5 & NSR \\
\hline $\mathrm{P} 1$ & 15,9 & 12,9 & 22,0 & 20,7 & 23,3 & 5,2 & 9,3 & 14,7 & 23,3 & 17,8 & 30,2 & 4,7 \\
\hline $\mathrm{P} 2$ & 23,7 & 17,2 & 19,0 & 16,4 & 11,6 & 12,1 & 19,4 & 17,8 & 23,3 & 10,1 & 15,5 & 14,0 \\
\hline P3 & 15,5 & 15,5 & 21,1 & 13,8 & 7,8 & 26,3 & 14,7 & 17,8 & 18,6 & 12,4 & 12,4 & 24,0 \\
\hline $\mathrm{P} 4$ & 11,6 & 15,1 & 22,0 & 23,7 & 22,8 & 4,7 & 13,2 & 14,7 & 22,5 & 18,6 & 25,6 & 5,4 \\
\hline $\mathrm{P} 5$ & 15,5 & 16,4 & 24,6 & 17,7 & 20,7 & 5,2 & 11,6 & 13,2 & 20,9 & 24,0 & 25,6 & 4,7 \\
\hline P6 & 23,7 & 19,0 & 19,4 & 15,1 & 13,4 & 9,5 & 21,7 & 12,4 & 17,8 & 16,3 & 21,7 & 10,1 \\
\hline $\mathrm{P} 7$ & 19,4 & 16,8 & 22,8 & 18,5 & 15,1 & 7,3 & 17,8 & 7,8 & 21,7 & 20,2 & 24,0 & 8,5 \\
\hline $\mathrm{P} 8$ & 16,4 & 9,1 & 25,0 & 19,0 & 22,8 & 7,8 & 15,5 & 9,3 & 18,6 & 19,4 & 31,0 & 6,2 \\
\hline P9 & 24,6 & 13,8 & 22,4 & 11,6 & 20,7 & 6,9 & 13,2 & 15,5 & 20,2 & 21,7 & 24,0 & 5,4 \\
\hline $\mathrm{P} 10$ & 11,6 & 12,1 & 15,9 & 23,7 & 31,9 & 4,7 & 7,8 & 10,9 & 15,5 & 21,7 & 36,4 & 7,8 \\
\hline $\mathrm{P} 11$ & 20,3 & 15,9 & 17,7 & 18,5 & 20,3 & 7,3 & 17,8 & 13,2 & 18,6 & 18,6 & 24,0 & 7,8 \\
\hline
\end{tabular}

Legenda: 1 = nenhuma importância $\mid 5=$ extrema importância $\mid$ NSR = não sei responder.

Fonte: elaboração própria.

A Tabela 2 traz a comparação das duas amostras ATE1_SUST e MAIS_SUST e também indica um crescimento do número de respostas de média a elevada importância (categorias 3 a 5) com o aumento do número de disciplinas cursadas. Nela, vê-se que ATE1_SUST tem apenas três (3) modas das respostas na categoria de média importância (P5, P7 e P8) e três (3) na categoria de extrema importância (P1, P4, P10). Os resultados da amostra MAIS_SUST revelam todas as modas nas categorias de média e elevada importância, sendo que sete (7) modas estão na categoria de extrema importância (P1, P8, P9, P10 e P11).

Outra diferença registrada diz respeito à contribuição dos contadores nas decisões sobre migração para computação em nuvem (P8). Na amostra ATE1_SUST, esta questão alcançou o percentual $(17,6 \%)$ de respostas "nenhuma importância" e cerca de $8 \%$ de respondentes não souberam se posicionar, indicando que muitos respondentes tendem a não saber do que se trata ou, quando sabem, não atribuem nenhuma importância. Por outro lado, os respondentes que cursaram maior número de disciplinas de sustentabilidade apresentam redução acentuada nesses percentuais, apresentando $12,1 \%$ para a ausência de importância e $5,1 \%$ para categoria de resposta "Não sei responder". 
A terceirização total ou parcial da infraestrutura e/ou serviços de TI, por meio da contratação de provedores de serviços de nuvem é vista hoje como a principal aliada das estratégias de sustentabilidade em TI/SI, facilitando a economia de recursos naturais e financeiros (SILVA; SOARES; GOMES, 2017). Além disso, a "computação em nuvem oferece flexibilidade e escalabilidade para os operadores de centros de dados quando a expansão é necessária sem a necessidade de estimar a demanda futura de serviços" (PAWLISH; VARDE, 2010, p. 51, tradução dos autores).

A Tabela 2 evidencia semelhanças nos resultados dos dois grupos de respondentes. Ressaltam-se as respostas sobre a contribuição dos contadores para a gestão do ciclo de vida dos equipamentos de TI (P4). Nas duas amostras, a percepção de importância dessa contribuição supera $80 \%$. Uma competência a ser adquirida pelos contadores é a compreensão dos ciclos de upgrade e substituição de equipamentos (UNCTAD, 2011).

Tabela 2 - Importância da contribuição dos contadores para as práticas de TI/SI Verde com respondentes agrupados número de disciplinas de Sustentabilidade cursadas (Frequência de respostas em\%)

\begin{tabular}{|c|c|c|c|c|c|c|c|c|c|c|c|c|}
\hline & \multicolumn{6}{|c|}{ ATE1_SUST (até 1 disciplina) } & \multicolumn{6}{|c|}{ MAIS_SUST ( 2 ou mais disciplinas) } \\
\hline & \multicolumn{6}{|c|}{ Respostas } & \multicolumn{6}{|c|}{ Respostas } \\
\hline & 1 & 2 & 3 & 4 & 5 & NSR & 1 & 2 & 3 & 4 & 5 & NSR \\
\hline $\mathrm{P} 1$ & 14,9 & 14,9 & 23,3 & 18,7 & 22,9 & 5,3 & 10,1 & 10,1 & 20,2 & 22,2 & 33,3 & 4,0 \\
\hline $\mathrm{P} 2$ & 23,3 & 19,8 & 17,2 & 13,4 & 13,4 & 13,0 & 19,2 & 11,1 & 29,3 & 16,2 & 12,1 & 12,1 \\
\hline $\mathrm{P} 3$ & 15,6 & 17,2 & 19,5 & 11,1 & 9,2 & 27,5 & 14,1 & 14,1 & 22,2 & 19,2 & 10,1 & 20,2 \\
\hline $\mathrm{P} 4$ & 12,6 & 14,1 & 22,9 & 21,8 & 23,3 & 5,3 & 11,1 & 17,2 & 20,2 & 22,2 & 25,3 & 4,0 \\
\hline P5 & 16,4 & 15,3 & 23,7 & 18,7 & 21,0 & 5,0 & 8,1 & 15,2 & 22,2 & 23,2 & 26,3 & 5,1 \\
\hline $\mathrm{P} 6$ & 24,4 & 15,3 & 19,8 & 13,4 & 16,8 & 10,3 & 19,2 & 20,2 & 16,2 & 21,2 & 15,2 & 8,1 \\
\hline P7 & 20,6 & 13,7 & 22,9 & 16,8 & 17,6 & 8,4 & 14,1 & 13,1 & 21,2 & 25,3 & 20,2 & 6,1 \\
\hline P8 & 17,6 & 8,8 & 24,4 & 17,9 & 23,3 & 8,0 & 12,1 & 10,1 & 18,2 & 22,2 & 32,3 & 5,1 \\
\hline P9 & 22,5 & 14,9 & 21,8 & 14,5 & 19,8 & 6,5 & 15,2 & 13,1 & 21,2 & 17,2 & 27,3 & 6,1 \\
\hline $\mathrm{P} 10$ & 10,7 & 11,5 & 16,0 & 24,8 & 31,3 & 5,7 & 9,1 & 12,1 & 15,2 & 18,2 & 39,4 & 6,1 \\
\hline P11 & 21,0 & 15,6 & 17,6 & 19,8 & 18,3 & 7,6 & 15,2 & 13,1 & 19,2 & 15,2 & 30,3 & 7,1 \\
\hline
\end{tabular}

Legenda: 1 = nenhuma importância $\mid 5$ = extrema importância $\mid$ NSR = não sei responder.

Fonte: elaboração própria.

Diante do exposto, se constata que os estudantes demonstraram estar bastante divididos sobre a importância da contribuição dos contadores para as práticas de sustentabilidade em tecnologia e sistemas de informação (TI/SI). Além disso, é possível perceber que conceitos eminentemente técnicos, como "computação paralela", ainda são um pouco distantes do vocabulário dos estudantes de contabilidade. 
Note-se que os alunos atribuem mais importância à contribuição dos contadores para práticas relacionadas à contabilidade gerencial do que à estrita preparação de demonstrações para usuários externos.

Por último, antes de passar aos testes estatísticos de diferenças de respostas, cumpre esclarecer, quanto à confiabilidade do instrumento, que o questionário de pesquisa apresenta coeficiente Alfa de Cronbach igual a 0,934, portanto, muito superior ao limite mínimo considerado como aceitável, 0,70 .

Analisa-se que os testes de média dos postos (Testes Não Paramétricos U de Mann Whitney) comprovaram, com relação aos efeitos das variáveis "quantidade de disciplinas sobre sustentabilidade cursadas" e "quantidade de disciplinas de TI/SI cursadas", a existência de diferenças estatisticamente significativas (Tabela 3).

No exame das amostras independentes ATE1_SUST (Cursou até 1 disciplina de sustentabilidade) e MAIS_SUST (Cursou 2 ou mais disciplinas de sustentabilidade) foram identificadas $45,45 \%(5 / 11)$ de diferenças estatisticamente significativas entre as respostas dos respondentes dos dois grupos. Enquanto que, com relação as amostras independentes ATE1_TI (Cursou até 1 disciplina de TI) e MAIS_TI (Cursou 2 ou mais disciplinas de sustentabilidade) foram identificadas apenas 18,18\% (2/11) de diferenças estatisticamente significativas entre as respostas dos respondentes dos dois grupos.

Tabela 3 - Comparação das respostas sobre a contribuição dos contadores para as práticas de sustentabilidade em tecnologia e sistemas de informação (TI/SI)

\begin{tabular}{l|l|l|l|l|l|l}
\hline \multirow{2}{*}{ Práticas } & \multicolumn{2}{|c|}{ Média de Postos } & \multicolumn{3}{c|}{ Média de Postos } & \\
\cline { 2 - 7 } & ATE1_SUST & MAIS_SUST & \multicolumn{1}{|c}{ P-Valor } & ATE1_TI & \multicolumn{1}{c}{ MAIS_TI } & P-Valor \\
\hline P1 & 164,09 & 192,64 & $0,014^{*}$ & 166,33 & 182,15 & 0,146 \\
\hline P2 & 154,13 & 168,14 & 0,212 & 155,72 & 162,18 & 0,538 \\
\hline P3 & 130,88 & 144,91 & 0,168 & 133,22 & 138,11 & 0,611 \\
\hline P4 & 171,19 & 174,12 & 0,802 & 172,35 & 171,36 & 0,928 \\
\hline P5 & 165,66 & 188,8 & $0,049^{*}$ & 164,7 & 185,07 & 0,062 \\
\hline P6 & 161,31 & 169,15 & 0,491 & 156,58 & 176,03 & 0,068 \\
\hline P7 & 161,53 & 181,13 & 0,088 & 158,56 & 182,38 & $0,027^{*}$ \\
\hline P8 & 161,69 & 184,18 & $0,05^{*}$ & 162,85 & 177,11 & 0,184 \\
\hline P9 & 162,98 & 186,68 & $0,042^{*}$ & 160,07 & 182,19 & $0,016^{*}$ \\
\hline P10 & 167,42 & 178,68 & 0,33 & 165,87 & 179,1 & 0,22 \\
\hline P11 & 160,96 & 184,71 & $0,04^{*}$ & 163,7 & 174,4 & 0,32 \\
\hline
\end{tabular}

* diferença estatisticamente significativa para p-valor $<0,05$

Fonte: elaboração própria. 
A Tabela 3 indica que os estudantes que cursaram duas ou mais disciplinas sobre sustentabilidade atribuem maior importância à contribuição dos contadores para as práticas de TI verde relacionadas ao consumo de energia (P1 e P9). O "setor de TI/SI consumiu 7\% da energia do planeta em 2012, alcançará 12\% em 2017 e continuará crescendo a uma taxa projetada de $7 \%$ a.a. até 2030" (COOK et al., 2017, p. 15, tradução dos autores). Os contadores devem contribuir para a contabilização dos custos e passivos ambientais (UNCTAD, 2011).

Outra prática em que a percepção de importância da amostra MAIS_SUST é superior à da amostra ATE1_SUST é a especificação de compras sustentáveis de TI (P5). As compras sustentáveis de TI priorizam a aquisição de "equipamentos cujos fabricantes estejam em conformidade com normas e regulamentos internacionais, privilegiando materiais recicláveis e evitando o uso de componentes considerados nocivos (chumbo, cobre, mercúrio, cadmio etc.) ao meio ambiente" (SILVA, SOARES e GOMES, 2017, p. 5).

No que diz respeito à consolidação e virtualização de servidores e dispositivos de armazenamento de dados (P7) houve diferença de opiniões entre os alunos em função do número de disciplinas de TI cursadas. Por tratar-se de tópico relacionado com a arquitetura de computadores, supõe-se que os alunos que cursaram duas ou mais disciplinas de TI/SI obtiveram melhor compreensão dessa prática de criação de ambientes virtuais que compartilham os mesmos sistemas operacionais, aplicações e infraestrutura.

Portanto, constata-se que o grupo de estudantes que cursou 2 (duas) ou mais disciplinas sobre sustentabilidade tem percepção de importância mais elevada acerca da "contribuição dos contadores para as práticas de sustentabilidade em TI/SI" e apresenta "scores" significativamente mais elevados para mais de $45 \%$ das práticas propostas. Por outro lado, a quantidade de diferenças estatisticamente significativas entre os grupos de respondentes separados pela quantidade de disciplinas de TI/SI, foi bem menor, revelando-se em menos de $20 \%$ das práticas propostas.

\section{CONSIDERAÇÕES FINAIS}

O presente trabalho tem por objetivo avaliar a importância de cursar disciplinas sobre sustentabilidade e Tecnologia da Informação/Sistema de Informação (TI/SI) para a formação da percepção de estudantes de graduação e pós-graduação stricto sensu em contabilidade, da 
Região Metropolitana do Rio de Janeiro, com relação à contribuição dos contadores para a adoção de práticas de sustentabilidade em TI/SI nas organizações.

Os resultados desta pesquisa confirmam os achados da literatura de que muitos alunos de ciências contábeis chegam ao final do curso sem ter nenhum contato com disciplinas de TI/SI e/ou Sustentabilidade. Outrossim, quando o fazem, geralmente cursam apenas uma disciplina e conceitos mais avançados de TI/SI ainda são desconhecidos dos alunos de ciências contábeis das IES pesquisadas.

Além disso, foi constatado que, na percepção dos respondentes, a contribuição mais importante dos contadores para a sustentabilidade em TI/SI foi "controlar e avaliar o desempenho de indicadores físicos e financeiros de TI”, por outro lado, uma das contribuições menos importantes foi "reportar desempenho ambiental de TI para usuários externos". Essa constatação revela que os alunos estão cientes da importância do papel gerencial do contador na atualidade. Indica, também, que os alunos estão orientados para o futuro em termos de mercado de trabalho, o que é um sinal positivo. Porém, é menor o reconhecimento da necessidade de a contabilidade fazer o reporte socioambiental.

Ademais, constatou-se que a quantidade de disciplinas cursadas de TI/SI e Sustentabilidade ao longo da vida acadêmica dos alunos tem a capacidade de influenciar a percepção de importância atribuída pelos respondentes acerca das contribuições dos contadores para essas áreas. Permite-se inferir que, os alunos que cursam maior quantidade dessas disciplinas têm mais facilidade para estabelecer conexões entre as funções e competências dos contadores nas organizações e as estratégias e práticas de sustentabilidade em TI/SI. O que não é algo trivial.

Destaca-se que as disciplinas que revelaram ter a maior capacidade de influenciar a percepção dos respondentes foram as disciplinas sobre sustentabilidade, que quando cursadas em maior quantidade, pelo menos duas disciplinas, geraram "scores" de percepção de importância significativamente mais altos para mais de $45 \%$ das práticas propostas. Essa constatação é importante, pois demonstra a relevância de estimular e ofertar nas grades curriculares maior quantidade dessas disciplinas, não apenas como optativas, mas como disciplinas obrigatórias, para uma formação integral dos discentes.

A inclusão de tais tópicos nas grades curriculares dos cursos de contabilidade favorece o desenvolvimento de competências transdisciplinares requeridas para o desenvolvimento da carreira no longo prazo. O crescimento da divulgação de relatórios de sustentabilidade requer 
contadores competentes para mensurar, interpretar e comunicar métricas de desempenho mais amplas e de longo prazo, compreendendo melhor o papel das organizações na sociedade. Se o contador não desempenhar seu papel no auxílio à adoção de práticas de sustentabilidade em TI/SI nas organizações, outros profissionais, tais como engenheiros e administradores, podem fazê-lo.

Esse estudo mostra que a baixa exposição dos alunos aos temas de sustentabilidade e TI/SI durante os cursos de graduação e pós-graduação em ciências contábeis torna menos provável que os futuros profissionais de contabilidade se importem com a adoção das práticas de sustentabilidade em TI/SI. Ao contrário, a exposição adequada dos discentes a tais temas pode iniciar uma mudança na profissão contábil, levando-os a serem mais interessados nos impactos ambientais e sociais dos negócios.

Os resultados dessa pesquisa revelam que as IES estudadas precisam revisar as grades curriculares dos cursos de contabilidade para ampliar o número de disciplinas obrigatórias sobre sustentabilidade e TI/SI, de modo a preparar seus alunos para uma posição de liderança na adoção das práticas de sustentabilidade nas organizações, de forma especial de TI verde. Este estudo foi realizado apenas com discentes de ciências contábeis. Assim, sugere-se que, em pesquisas futuras, sejam avaliadas as percepções de profissionais da contabilidade, isto é, de contadores e técnicos praticantes.

Outras sugestões de estudos futuros são examinar a percepção dos empregadores e dos professores sobre a adequação das grades curriculares dos cursos de contabilidade com relação ao tema de sustentabilidade em TI/SI.

Uma limitação ocasionada pelo compromisso assumido com as IES, para autorização da realização da pesquisa em suas instalações, foi a não divulgação de resultados por instituição.

Por último, cabe ressalvar que a principal limitação desta pesquisa é o fato de ter-se utilizado de amostra não probabilística, uma vez que os respondentes foram selecionados por critério de conveniência dos pesquisadores. Por este motivo, apesar do número de respondentes ter sido bastante significativo, não se pode fazer generalizações a partir deste estudo. 


\section{REFERÊNCIAS}

ALMEIDA et al. Sistemas de Informação: a Percepção dos Egressos do Curso de Ciências Contábeis Acerca da Contribuição da Disciplina de Análise de Sistemas Contábeis e Administrativos para a Formação Profissional. Revista de Gestão e Contabilidade da UFPI - GєCont, v. 2, n. 1, p. 133-151, jan./jun., 2015.

BOSE, R.; LUO, C. Integrative framework for assessing firm's potential to undertake Green IT initiatives via virtualization - A theoretical perspective. Journal of Strategic Information Systems, v. 20, n. 1, p. 38-54, 2011.

; LUO, C. Green IT adoption: a process management approach. International Journal of Accounting and Information Management, v. 20, n. 1, p. 63-67, 2012.

BOULIANNE, E. How should information technology be covered in the accounting program? Canadian Journal of Administrative Sciences, v. 33, n. 4, p. 304-317, 2016.

BRANDALISE, L. T. et al., O Reflexo da Disciplina de Educação Ambiental na Percepção e Conduta dos Universitários, Pretexto 2014, v. 15, n. 4, p. 11-26, out. /dez., 2014.

CALIXTO, L. O ensino da contabilidade ambiental nas universidades brasileiras: um estudo exploratório. Revista Universo Contábil, v. 2, n. 3, p. 65-78, set./dez., 2006.

CAMPOS, L. C.; LEMES, S. Análise dos conteúdos de tecnologia da informação sugeridos pelo currículo mundial frente à percepção dos profissionais da área contábil. Revista de Administração e Contabilidade, v. 6, n. 1, jan./abr., p. 22-41, 2014.

CARMO, L. M.; GOMES, M. Z.; MACEDO, A. S. M. Análise da Importância das Competências em Tecnologia e Sistemas de Informação para a Formação de Contadores sob a Perspectiva de Gênero. Sociedade, Contabilidade e Gestão, v. 10, n. 3, set./dez., 2015.

CASTRO, B. R. V. et al. O Marketing Verde na Tecnologia da Informação: Percepções das Atitudes e Comportamentos dos Profissionais de TI e Ações para Incrementar o Marketing Verde nesse Setor. Revista de Gestão Ambiental e Sustentabilidade, v. 5, n. 1, p. 45-60, 2016.

CAVAlCANTE, D. S. et al. Adequação dos Currículos dos Cursos de Contabilidade das Universidades Federais Brasileiras ao Currículo Mundial de Contabilidade e o Desempenho no Enade. Pensar Contábil, v. 13, n. 50, p. 42-52, jan./abr. 2011. 
CHANG, S. et al. Analysis of the effects of an environmental accounting system on accountants based on the organizational reform theory. In: PACIFIC ASIA CONFERENCE ON INFORMATION SYSTEMS. Anais... Brisbane, Australia, QUT, 2011.

CHAVES, S. A questão dos riscos em ambientes de computação em nuvem. Dissertação (Mestrado em Administração). USP. São Paulo, Brasil, 2011.

CONCEIÇÃO et al. Comparação do nível de conhecimento sobre contabilidade social e ambiental dos estudantes ingressos e formandos do curso de ciências contábeis da Universidade Federal da Bahia. GєCont, v. 1, n. 2, jul./dez. 2014.

CONSElHO FEDERAL DE CONTABILIDADE. Proposta Nacional de Conteúdo para o Curso de Graduação em Ciências Contábeis. 2009.

COOK, G. et al. Clicking Clean: Who is winning the race to build a green internet? Greenpeace Inc.: Washington - DC, 2017. 101p.

COYNE, J. G.; COYNE, E. M.; WALTER, K. B. Accountants and the Tech: A Game Changer? Strategic Finance, p. 41-47, mar., 2017.

CZESNAT, A. O.; CUNHA, J. V. A.; DOMINGUES, M. J. C. S. Análise comparativa entre os currículos dos cursos de ciências contábeis das universidades do Estado de Santa Catarina listadas pelo MEC e o Currículo Mundial proposto pela ONU/UNCTAD/ISAR. Gestão \& Regionalidade, v. 25, n. 75, p. 22-30, set./dez., 2009.

DALLABONA, L. F.; CUNHA, P. R.; RAUSCH, R. B. Inserção da área ambiental na matriz curricular do curso de Ciências Contábeis: um estudo das IES da região Sul do Brasil. Enfoque: Reflexão Contábil, v. 31, n. 3, p. 7-22, set./dez., 2012. Doi: 10.4025/enfoque. v31i3.15302.

DALVI-ESFAHANI, M.; RAMAYAH, T.; NILASHI, M. Modelling upper echelons' behavioural drivers of Green IT/IS adoption using an integrated Interpretive Structural Modelling - Analytic Network Process approach. Telematics and Informatics, v. 34, p. 583-603, 2017.

DI SALVO, A. L. A. et al. Can cloud computing be labeled as "green"? Insights under an environmental accounting perspective. Renewable and Sustainable Energy Reviews, n. 69, p. 514-526, 2017. 
DREHER, M. T.; SEVEGNANI, L. Descobrir o valor em aprender sobre sustentabilidade: um caso de ensino no programa stricto sensu em administração, Administração: Ensino e Pesquisa, v. 13, n. 4, p. 805-823, out./dez., 2012.

EL-DALAHMEH, S. M. Information Technology (IT) Competencies Desired in New Accounting Graduates: A Survey in Jordanian Business Environment Suleiman. International Journal of Business and Management, v. 12, n. 5, p. 202-208, 2017. Doi: 10.5539/ijbm. v12n5p202.

ERFURTH, A. E. et al. O ISAR/UNCTAD, as Diretrizes curriculares brasileiras e as disciplinas de Contabilidade de Custos: reflexões na área de Contabilidade. In: XVI CONGRESSO BRASILEIRO DE CUSTOS. Anais... Fortaleza, Brasil, 2009.

FARIAS, E. L. Desafios na implementação do XBRL no Brasil: um estudo utilizando a teoria de difusão de inovações. Dissertação (Mestrado em Controladoria e Contabilidade). USP, São Paulo, Brasil, 2014.

FEIL, A. A. et al. Análise do nível de conhecimento do profissional contábil acerca da contabilidade ambiental e suas variáveis intervenientes. Revista Ambiente Contábil. v. 9. n. 1, p. 223-245, jan./jun. 2017.

FERREIRA, H. L. et al. A tecnologia da informação nas revistas de contabilidade nacionais: um estudo bibliométrico. In: CONGRESSO INTERNACIONAL DE GESTÃO DA TECNOLOGIA E SISTEMAS DE INFORMAÇÃO. Anais... São Paulo, Brasil, USP, 2018.

FRIEDMAN, T. L. O mundo é plano: uma breve história do século XXI. $2^{\mathrm{a}}$. Ed. Rio de Janeiro: Objetiva, 2007. 557pp.

GUENTHER, E.; ENDRIKAT, J.; GUENTHER, T. W. Environmental management control systems: A conceptualization and a review of the empirical evidence. Journal of Cleaner Production, v. 136, p. 147-171, 2016.

IFAC. International Accounting Education Standards Board: Handbook of International Education Pronouncements. New York, 2017. 111 p.

JIN, X. et al. Green Data Centers: A Survey, Perspectives, and Future Directions. arXiv: 1608.00687 [cs. DC], v. 1, n. -, 2016. 
JNR, B. A.; MAJID, M. A. Green IS for Sustainable Decision Making in Software Management. Journal of Soft Computing and Decision Support Systems, v. 3, n. 3, p. 2034, 2016.

KANELLOU, A.; SPATHIS, C. Accounting benefits and satisfaction in an ERP environment. International Journal of Accounting Information Systems, v. 14, p. 209-234, 2013.

KRAHEL, J. P.; VASARHELYI, M. A. AIS as a Facilitator of Accounting Change: Technology, Practice, and Education. Journal of Information Systems, v. 28, n. 2, p. 1-15, outono, 2014.

LIU, C.; O'FARRELL, G. The role of accounting values in the relation between XBRL and forecast accuracy. International Journal of Accounting and Information Management, v. 21, n. 4, p. 297-313, 2013.

LOW, et al. Accounting Employers' Expectations - The Ideal Accounting Graduates. eJournal of Business Education \& Scholarship of Teaching, v. 10, n. 1, p. 36-57, 2016.

MAITINO NETO, R.; FAXINA, J. M. TI verde e sustentabilidade. Revista de Ciências Exatas e Tecnologia, v. 7, n. 7, p. 159-174, 2014.

MARTINS, P. M. S. Modelo de decisão para avaliar a utilização sustentável das tecnologias de informação. Dissertação (Mestrado em Engenharia e Gestão Industrial). Universidade Nova de Lisboa, Lisboa, Portugal, 2012.

MATTOS, C. A.; LAURINDO, F. J. B. Bibliometric research on integration of ERP systems and sustainability: Trends for future research. In: $12^{\mathrm{TH}}$. INTERNATIONAL CONFERENCE IN INFORMATION SYSTEMS \& TECHNOLOGY MANAGEMENT. Anais... São Paulo, Brasil, USP, 2015.

MCKINNEY JR, E.; YOOS II, C. J.; SNEAD, K. The need for 'skeptical' accountants in the era of Big Data. Journal of Accounting Education, v. 38, p. 63-80, 2017.

MERHOUT, J. W; CALLISON, M. M.; SCHILLER, S. Environmental Management Information Systems: A Conceptual Overview and Review of Vendors. In: ELEVENTH MIDWEST ASSOCIATION FOR INFORMATION SYSTEMS CONFERENCE. Anais... Milwaukee, EUA, 2016.

MINISTÉRIO DA EDUCAÇÃO. Resolução CNE/CES 10, de 16 de dezembro de 2004. Institui as Diretrizes Curriculares Nacionais para o Curso de Graduação em Ciências 
Contábeis, bacharelado, e dá outras providências. 2004.

MOLLA, A. et al. E-readiness to G-readiness: Developing a green information technology readiness framework. In: $19^{\mathrm{TH}}$. AUSTRALASIAN CONFERENCE ON INFORMATION SYSTEMS. Anais... Christchurch, Nova Zelândia, University of Canterbury, 2008.

MÓR, S. D. K. et al. Eficiência energética em computação de alto desempenho: Uma abordagem em arquitetura e programação para green computing. In: XXX CONGRESSO DA SOCIEDADE BRASILEIRA DE COMPUTAÇÃO. Anais... Belo Horizonte, Brasil, PUCMG, 2010.

MURUGESAN, S. Harnessing green IT: Principles and practices. IT professional, v. 10, n. 1, p. 24-33, jan./fev. 2008.

OLIVEIRA, O. J.; PINHEIRO, C. R. M. S. Implantação de sistemas de gestão ambiental ISO 14001: uma contribuição da área de gestão de pessoas. Gestão \& Produção, v. 17, n. 1, p. 51-61, 2010.

OWEN, G. Integrated Reporting: A Review of Developments and their Implications for the Accounting Curriculum. Accounting Education: an international journal, v. 22, n. 4, p. 340-356, 2013.

PARAWIYATI et al. Perceptions of Academics and Practitioners against Social Responsibility Accounting Learning in Higher Education. Research Journal of Finance and Accounting, v. 5, n. 24, p. 128-138, 2014.

PAWLISH, M.; VARDE, A. S. A Decision Support System for Green Data Centers. In: PROCEEDINGS OF THE 3RD WORKSHOP ON PH. D. STUDENTS IN INFORMATION AND KNOWLEDGE MANAGEMENT. Anais... Toronto, Canadá, York University, 2010.

PETRINI, M.; POZZEBON, M. Managing sustainability with the support of business intelligence: Integrating socio-environmental indicators and organizational context. Journal of Strategic Information Systems, v. 18, p. 178-191, 2009.

PINCUS, K. V. et al. Forces for change in higher education and implications for the accounting academy. Journal of Accounting Education. 2017. http://dx.doi.org/10.1016/j.jaccedu.2017.06.001.

REGINATO, L.; NASCIMENTO, A. M. Um estudo de caso envolvendo business intelligence como instrumento de apoio à controladoria. Revista Contabilidade e Finanças, Edição 30 
Anos de Doutorado, p. 69-83, jun. 2007.

REIS, I. W. Investigação de aspectos verdes na implantação de um data Center na área industrial de Suape-PE. 2009. Dissertação (Mestrado Profissional em Ciência da Computação). UFPE, Recife, Brasil, 2009.

RICCIO, E. L. Efeitos da Tecnologia de Informação na Contabilidade - estudo de casos de implementação de sistemas empresariais integrados - ERP. Tese (Livre-docência). USP, São Paulo, Brasil, 2001.

RICHTER, R. M. TI Verde: Sustentabilidade por meio da Computação em Nuvem, 2012. Disponível em: <http://www.cps.sp.gov.br/pos-graduacao/workshopdepos-graduacao-epesquisa/007-workshop-2012/workshop/trabalhos/desenvgestti/ti-verde-sustentabilidade.pdf> Acesso em: 27 set. 2016.

RODRIGUES, W. A. Sistemas de gestão ambiental: compatibilização dos objetivos econômicos, estratégicos, sociais e ambientais nas organizações empresariais. Revista Interface Tecnológica, v. 7, n. 1, p. 11, 2010.

SANTOS, A. C.; DOMINGUES, M. J. C. S.; RIBEIRO, M. J. Um estudo sobre o nível de aderência dos cursos de ciências contábeis das instituições paranaenses listadas no MEC, ao currículo mundial. In: V CONGRESSO DA ASSOCIAÇÃO NACIONAL DOS PROGRAMAS DE PÓS-GRADUAÇÃO EM CIÊNCIAS CONTÁBEIS. Anais... Vitória, Brasil, 2011.

SAYEED, L.; GILL, S. Exploratory Study on Environmental Sustainability and IT Use. In: $14^{\mathrm{TH}}$ AMERICAS CONFERENCE ON INFORMATION SYSTEMS. Anais.... Toronto, Canadá, 2008.

SILVA, J. F. P.; RODRIGUES, R. N. Sustentabilidade empresarial: O paradigma da formação do profissional contábil $x$ Responsabilidade social das Empresas. In: $X$ SEMINÁRIO UFPE DE CIÊNCIAS CONTÁBEIS. Anais... Recife, Brasil, UFPE, 2016.

SILVA, J. P. A revolução digital na divulgação de informações contábeis: benefícios e riscos percebidos na adoção da XBRL (eXtensible Business Reporting Language) por empresas no Brasil. Dissertação (Mestrado em Contabilidade). UFRJ, Rio de Janeiro, Brasil, 2016.

SILVA, R. J.; SOARES, J. E. V. M.; GOMES, M. Z. Green IT (TI Verde): Uma Análise Bibliográfica sob o Enfoque Interdisciplinar de Sistemas de Informação e Ciências Contábeis. In: V Conferência Sulamericana de Contabilidade Ambiental Valores Humanos e Consumo 
Sustentável. Anais...Brasília: V CSCA, 2017.

SILVA, S. C. Desafios dos programas de graduação em Ciências Contábeis face às mudanças emergentes na pós-modernidade. Tese (Doutorado em Controladoria e Contabilidade). USP, São Paulo, Brasil, 2014.

SLEDGIANOWSKI, D.; GOMAA, M.; TAN, C. Toward integration of Big Data, technology and information systems competencies into the accounting curriculum. Journal of Accounting Education, v. 38, n. -, p. 81-93, 2017.

STINDT, Dennis et al. An Environmental Management Information System for Closing Knowledge Gaps in Corporate Sustainable Decision-Making. In: THIRTY FIFTH INTERNATIONAL CONFERENCE ON INFORMATION SYSTEMS. Anais... Auckland, Nova Zelândia, University of Auckland, 2014.

UNCTAD, Revised Model Accounting Curriculum (MC), New York, 2011.

VARELO, E. M. et al. Ensino da contabilidade ambiental nas instituições de ensino superior brasileiras. In: II CONFERÊNCIA CSEAR SOUTH AMERICA. Anais... Ribeirão Preto, Brasil, USP, 2011.

VERGARA, S. C. Projetos e Relatórios de Pesquisa em Administração, 7. Ed. São Paulo: Atlas, 2006. $96 \mathrm{pp}$.

VIEIRA, C. S.; MEIRELES, F. S.; CUNHA, M. A. Fatores que influenciam o indivíduo na utilização da Computação em Nuvem. In: INTERNATIONAL CONFERENCE ON INFORMATION RESOURCES MANAGEMENT. Anais... Ottawa, Canadá, 2015.

WAlterbuSCH, M.; MARTENS, B.; TEUTEBERG, F. A Decision Model for the Evaluation and Selection of Cloud Computing Services: A First Step Towards a More Sustainable Perspective. International Journal of Information Technology \& Decision Making. v. 14, n. 2, p. 253-285, 2015.

WEIZENMANN, C. A. A discussão sobre a inclusão da disciplina de contabilidade ambiental no currículo dos cursos de ciências contábeis. Trabalho de Conclusão de Curso (Graduação em Ciências Contábeis). UFRGS, Porto Alegre, Brasil, 2011.

WESTPHALL, C. B.; VILlaRREAL, S. R. Princípios e tendências em Green Cloud Computing. Revista Eletrônica de Sistemas de Informação, v. 12, n. 1, p. 1-19, 2013. 
WILLIAMS, D. R.; THOMOND, P.; MACKENZIE, I. The Greenhouse Gas Abatement Potential of Enterprise Cloud Computing. In: PROCEEDINGS OF THE FIRST INTERNATIONAL CONFERENCE ON INFORMATION AND COMMUNICATION TECHNOLOGIES FOR SUSTAINABILITY. Anais... Zurich, Suíça, ETH Zurich, 2013.

YU, S. C.; CHURYK, N. T.; CHANG, A. C. Are students ready for their future accounting careers? Insights from observed perception gaps among employers, interns, and alumni. Global Perspectives on Accounting Education, v. 10, n. -, p. 1-15, 2013. 